\section{Sex and psychological need in triadic bargaining}

\author{
JAMES L. PHILLIPS, JOEL ARONOFF, and LAWRENCE MESSÉ \\ Michigan State University, East Lansing, Mich. 48823
}

Differences in bargaining behavior in a three-person coalition game were examined as a function of motivation-the need for safety and the need for self-esteem-and sex. Males tended to revise initial demands for reward downward over a bargaining session to a greater extent than did females. Ss high in safety needs tended to underrate the value of their own resources, but an attempt to account for the sex difference in terms of a need hierarchy was unsuccessful.

Vinacke and his coworkers (Vinacke, 1959; Bond \& Vinacke, 1961, Wesugi \& Vinacke, 1963; Amidjaja \& Vinacke, 1965) have reported systematic differences between males and females with respect to the outcomes of triadic coalition-formation studies. These studies have indicated that males tend to form coalitions which exclude that person who is highest on some resource dimension; females, on the other hand, tend not to discriminate among themselves with respect to resources. Vinacke (1969) has argued that these results derive from the exploitative character of males and the accommodative character of females.

Attempts to design experiments permitting a more detailed examination of the coalition formation process have been made by Phillips \& Nitz (1968) and by Phillips $\&$ Cole (1970). Both studies failed to find sex differences with respect to the differential frequencies with which $\mathrm{Ss}$ make coalition attempts as a function of resources. Further, Phillips \& Cole (1970) were unable to replicate Vinacke's sex differences in coalition pattern, but they did find a significant sex difference with respect to bargaining.

The Phillips and Cole result showed a significant change from the first offer to the final agreement for males but no such change for females. This result, along with others, led Phillips and Cole to propose a revision of Vinacke's accommodative-exploitative distinction. According to Phillips and Cole, both males and females are concerned with the outcome of the game, but they adopt different strategies. The typicil coalition-formation game allows for

*This research was conducted under the auspices of the Cooperation/Conflict Research Group at Michigan State University and supported by the Computer Institute for Social Science Research and a National Science Foundation Institutional Grant for Science. We wish to thank Ronald Junttonen, Jack Dawson, and Ronald Michelini for their help in running Ss. four distinct outcomes: (1) being a member of the winning coalition and receiving the larger share of the payoff; (2) being a member of the winning coalition and receiving an equal share of the payoff; (3) being a member of the winning coalition and receiving the smaller share of the payoff; and (4) being excluded from the winning coalition. Males, according to Phillips and Cole, adopt a strategy that maximizes their chances of obtaining the first of these four outcomes and that does not discriminate among the other three outcomes. This strategy is called "playing to win." Alternatively, females are presumed to adopt a strategy that minimizes their chances of obtaining the fourth outcome and that does not discriminate among the first three outcomes. This failure to discriminate among the first three outcomes might be mistakenly interpreted as an orientation toward something other than winning-an orientation toward the social interaction aspects of the game-but it is more accurately characterized as a variation of a minimax strategy. This strategy will be referred to as "playing to avoid losing."

The need-hierarchy theoretical framework developed by Maslow (1954) seems particularly relevant to $\mathrm{th}$ is playing-to-win vs playing-to-avoid-losing distinction. The person whose predominant need is for safety, that is, who seeks security and is unsure of his ability to succeed in any given situation, should have a clear which minimizes his chances of losing. Thus, the safety-oriented person would be expected to choose a strategy which was likely to provide nim with some positive payoff rather than attempt to maximize over a set of positive payoffs. Therefore, a safety-oriented person would tend to play the "avoid losing" strategy. On the other hand, the person whose predominant need is for self-esteem, that is, who needs to demonstrate his competence both to himself and to preference for that bargaining strategy others, would tend not to be satisfied with just avoiding losing. The esteem-oriented person would be expected to choose that strategy which maximized his chances of obtaining the larger share of the payoff, that is, the "playing to win" strategy. That safety and esteem needs have a marked influence on the development of group structure has been demonstrated in a field experiment by Aronoff (1967, 1970) and in the laboratory by Aronoff \& Messé (1971).

DeYoung \& Phillips (1970) have developed an extension of the political convention paradigm for coalition formation (Gamson, 1961; Chertkoff, 1966; Phillips \& Nitz, 1968), in which the amount of resources controlled by an $S$ is objectively related to his "power" in the situation. In the basic political convention paradigm, each of three $S s$ is assigned some number of votes. No $\mathrm{S}$ has a majority of these votes, so any two Ss can coalesce to obtain a majority. In the DeYoung \& Phillips (1970) variation, a number of uncommitted votes are added, to be distributed randomly after the formation of a coalition. It is possible for the $S$ who is left out of the coalition to obtain a sufficient number of these uncommitted votes to defeat the coalition.

In the uncommitted-vote variation of the political convention paradigm, Ss high in esteem needs should demand and receive a proportion of the payoff commensurate with their contribution (number of votes) to the coalition. Ss high on safety needs should make more moderate demands and should be willing to accept less than their "fair share" of the payoff. This same pattern would be expected in the no-uncommitted variation, except that high-esteem Ss should be willing to moderate their initial demands and accept essentially an equal share of the payoff.

$$
\text { SUBJECTS }
$$

Approximately 1,000 male and female undergraduates at Michigan State University, in response to an advertisement in the student newspaper, volunteered for an initial testing session to qualify for participation in subsequent research for which they would receive monetary compensation. These Ss were administered the sentence completion test discussed in Aronoff \& Messé (1971). On the basis of their responses to this test, Ss were classified as either high or low on safety needs and as either high or low on esteem needs. The interscorer reliabilities for this classification were shown to be satisfactory by Aronoff $(1967,1970)$. Of that group high in esteem needs (and low in safety 
needs), 54 males and 48 females were selected for participation in the present study. Of that group high in safety needs (and low in esteem needs), 57 males and 63 females were selected. These Ss were formed into triads that were homogeneous with respect to both sex and need. Thus, there were 18 high-esteem male triads, 16 high-esteem female triads, 19 high-safety male triads, and 21 high-safety female triads.

\section{PROCEDURE}

Each triad participated in two coalition-formation games. For approximately half of the triads in each condition, the uncommitted-vote game was played first, followed by the no-uncommitted-vote game. This order was reversed for the other half. In both games, one triad member was assigned randomly to a 60-vote position, one to a 100-vote position, and the third to a 140-vote position. In the uncommitted-vote game, Ss were informed that 250 uncommitted votes would be distributed at random following the formation of a coalition. Ss were also informed that they would be paid $\$ 1.00$ for participation and that, in addition, one of the two games (to be determined randomly after both games were completed) would have a $\$ 3.00$ payoff, to be distributed as they decided in the game itself. Thus, Ss played each game as if a payoff of $\$ 3.00$ was at stake.

The Ss were separated from one another and from $E$ by a table divider. Slots were provided in the divider for Ss to pass messages to $\mathrm{E}$. At the beginning of each game, $E$ explained the rules and answered all questions. Each $S$ then indicated to $E$ that triad member with whom he wished to form a coalition. As soon as a mutual choice occurred, $E$ announced that the two players wished to form a coalition. At this point, the $S$ who had the greater number of votes was allowed to make an initial demand. This demand was for some amount of money less than or equal to the $\$ 3.00$ payoff. If the receiver of the demand accepted, the coalition was formed and the game was over. If the receiver rejected the demand, the sender was allowed to make a second demand. If the receiver rejected three demands, the bargaining was discontinued and the game was begun anew. In the no-uncommittedvote game, the coalition was automatically the winner. In the uncommitted-vote game, $E$ announced the distribution of the uncommitted votes, and that player or coalition with the majority of the votes was declared the winner. After both games were completed, the game for which the payoff was given was selected, Ss were given their money, and the purpose of the experiment was explained.

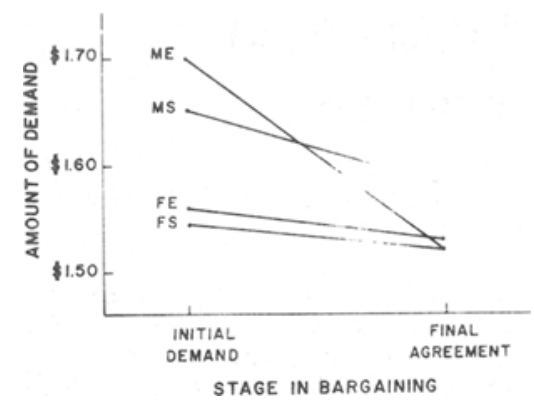

Fig. 1. Amount of demand for initial demand and final agreement for each of four experimental groups (no uncommitted votes).

\section{RESULTS}

The order in which the two games were played was counterbalanced within each of the four experimental groups. An analysis showed that this counterbalance had no effect on either the initial demand of the stronger coalition partner or on the final agreement reached by the coalition, so both orders were pooled for further analysis.

The demands of the stronger coalition partner were analyzed using a $2^{4}$ factorial ANOVA with repeated measures on two factors. The factors were: (1) initial demand (ID)/final agreement (FA), (2) uncomitted votes (UC)/no uncomitted votes ( $\overline{\mathrm{UC}}$ ), (3) safety (S)/esteem (E), and (4) males (M)/females (F). Because of the unequal cell size, an unweighted means analysis was performed. This analysis revealed that the following effects were significant at $\alpha=.05$ or beyond: the ID-FA effect, the ID-FA by Sex interaction, the ID-FA by Game Type by Need interaction, and the four-way interaction of all factors. A comparison of Fig. 1 with Fig. 2 is helpful in interpreting these results. Because of the significant four-way interaction, an analysis of simple effects was conducted. This analysis revealed that the final agreement was

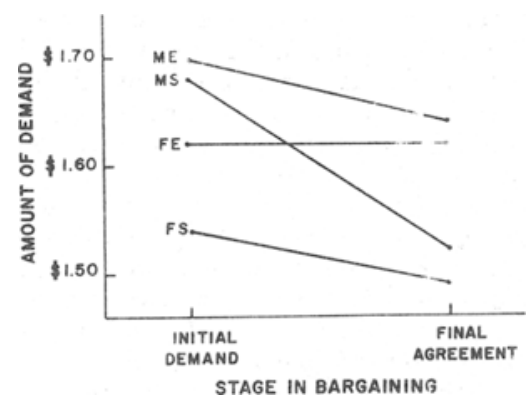

Fig. 2. Amount of demand for initial demand and final agreement for each of four experimental groups (uncommitted votes). significantly $(a \div .05)$ less than the initial demand for both safety and esteem male groups for both the UC and $\overline{\mathrm{UC}}$ game types. The effect was most pronounced for the male esteem (ME) group in the $\overline{U C}$ game and for the male safety (MS) in the UC game. For the ME group, the final agreement was higher in the UC game than in the $\overline{\text { UC }}$ game.

\section{DISCUSSION}

The significant ID-FA by Sex interaction replicates the finding by Phillips \& Cole (1970) that males revise their demands downward over a bargaining session to a greater extent than do females. In the $\overline{\mathrm{UC}}$ game this would appear to be because females begin with a lower initial demand than males, but this was not clearly operating in the UC game. Although the female group means were always lower on initial offer than were the male group means, the analysis of simple effects did not reveal a significant sex difference on initial offer. The significant ID-FA by Sex interaction, along with the absence of a significant ID-FA by Need interaction did not support the hypothesis that previously obtained sex differences could be accounted for in terms of the specific psychological needs examined in this study.

The analysis of the uncommitted vote game is particularly interesting, both because sex differences have not previously been examined in this situation and because of the marginally significant effects of need that were obtained in this game. Figure 2 indicated that males tend to make greater demands than females in this situation. As noted above, this effect failed to reach statistical significance, but it is consistent with previously reported results. The male safety (MS) group showed a significant decline (as in the $\overline{\mathrm{UC}}$ game), thus indicating that males with high safety needs did not differentiate between a situation in which their resources had objective validity in bargaining (the UC game) and a situation in which such objective validity was absent (the $\widehat{\mathrm{UC}}$ game). Although the difference was not significant, the MS group actually achieved a smaller share in the UC game than in the $\overline{U C}$ game. Although the male esteem (ME) group also showed a significant decline in the amount demanded, this group achieved a significantly greater share of the payoff in the UC game than in the $\overline{\mathrm{UC}}$ game. With respect to females, there was a greater disparity between the demands of the FE and FS groups in the UC game than in the $\overline{U C}$ game. This effect, though only marginally significant $(p<.10)$ was consistent with the results for males and seems to suggest that while high safety needs 
lead to an underevaluation of one's resource value in a bargaining situation, high esteem needs lead to a more realistic appraisal of these resources.

\section{REFERENCES}

AMIDJAJA, I. R., \& VINACKE, W. E Achievement, nurturance, and competition in male and female triads. Journal of Personality \& Social Psychology, 1965, 2, 447-451.

ARONOFF, J. Psychological needs and cultural systems. Princeton, N.J: Van Nostrand, 1967.

ARONOFF. J. Psychological needs as a determinant in the formation of economic structures: A confirmation. Human Relations, 1970, 23, 123-138.

ARONOFF, J., \& MESSÉ, L. Motivational determinants of small group structure. Journal of Personality \& Social Psychology, 1971, in press.

BOND, J. R., \& VINACKE, W. E. Coalitions in mixed-sex triads. Sociometry, 1961 , 24, 61-75.

CHERTKOFF, J. M. The effects of probability of future success on coalition formation. Journal of Experimental Social Psychology, 1966, 2, 265-277.
DeYOUNG, G.. \& PHILIIPS, J. L. Temporal stability of the power inversion effect in a three-person bargaining game. Presented at the annual meetings of the Rocky Mountain Psychological Association. Salt Lake City, Utah, May 8 , 1970.

GAMSON, W. A. An experimental test of a theory of coalition formation. American Sociological Review, 1961, 26, 565-573.

PHILLIPS, J. L., \& COLE, S. G. Sex differences in triadic coalition formation strategies. In J. L. Phillips and T. L. Conner (Eds.), Studies of conflict. conflict reduction and alliance formation. Report 70-1 of the Cooperation/Conflict Research Group, Michigan State University, 1970, pp. 154-176.

PHILLIPS, J. L. \& NITZ, L. H. Social contacts in a three person "political convention" situation. Journal of Conflict Resolution, 1968, 12, 206-214.

MASLOW, A. Motivation and personality. New York: Harper, 1954

WESUGI, R. K., \& VINACKE, W. E. Strategy in a feminine game. Sociometry, 1963, 26, 75-88.

VINACKE, W. E. Sex roles in a three person game. Sociometry, 1959,22, 343-360.

VINACKE, W, E. Variables in experimental games: Toward a field theory. Psychological Bulletin, 1969, 71, 293-318. uncertainty is reduced, uncertainty being defined in information theory terms as the probability of stimulus occurrence. This hypothesis implies that resistance to habituation of an orienting reaction is an increasing function of the uncertainty or information value of an orienting stimulus.

Some support for this prediction comes from a study by Lovibond (1969), who reported that habituation of the GSR component of the orienting reaction to a visual stimulus reinforced by a loud tone was a function of the uncertainty of the reinforcement schedule. Or \& Stern (1969), however, observed in a reaction-time study that resistance to habituation of the GSR and EEG components of the orienting reaction was not determined by the information value of the stimulus.

Both these studies employed signal or reinforced stimuli in the habituation series, though this does not appear to be a necessary condition for Sokolov's hypothesis. In fact, Or \& Stern (1969) suggested that in their study the reinforcement procedure may have been a source of interference.

The following study was undertaken to examine Sokolov's hypothesis for the case of habituation to nonsignal stimuli. Three stimulus series were constructed such that the occurrence of a stimulus in a series conveyed one, two, or three bits of information, and habituation of the orienting reaction was studied in terms of the GSR and finger pulse volume (FPV) components.

\section{SUBJECTS}

Thirty-six female undergraduates, with the age range of 17 to 25 years, volunteered for the study.

APPARATUS

Three sets of 16 photographic slides were prepared. One set contained eight each of the letters $A$ and $B$; a second set contained four each of the letters $A, B, C, D$; and the third set contained two each of the letters $A, B, C, D, E$, $F, G, H$. The occurrence of a stimulus within each of these three sets may be considered to convey one, two, or three bits of information, respectively.

The 16 slides within a set were presented in random order using a Kodak Carousel projector with a 250-mm lens. The exposure duration of each slide was $10 \mathrm{sec}$, and the onset of one slide was coincident with the offset of the previous slide. Presentation rate was controlled by a Kodak interval timer.

The slides were projected onto a $450 \times 300 \mathrm{~mm}$ screen, situated $2 \mathrm{~m}$ in front of $S$. Light intensity on the surface of the screen with an exposed slide was $230 \mathrm{fc}$. Slide presentation
Sokolov (1966) has proposed that the orienting reaction is evoked whenever a stimulus creates uncertainty and habituates as the 